This item was submitted to Loughborough's Research Repository by the author.

Items in Figshare are protected by copyright, with all rights reserved, unless otherwise indicated.

\title{
Addition of pectin-alginate to a carbohydrate beverage does not maintain gastrointestinal barrier function during exercise in hot-humid conditions better than carbohydrate ingestion alone
}

\section{PLEASE CITE THE PUBLISHED VERSION}

https://doi.org/10.1139/apnm-2020-0118

\section{PUBLISHER}

NRC Research Press (Canadian Science Publishing)

\section{VERSION}

AM (Accepted Manuscript)

\section{PUBLISHER STATEMENT}

This paper was accepted for publication in the journal Applied Physiology, Nutrition and Metabolism and the definitive published version is available at https://doi.org/10.1139/apnm-2020-0118.

\section{LICENCE}

CC BY-NC-ND 4.0

\section{REPOSITORY RECORD}

Flood, Tessa R., Stefano Montanari, Marley Wicks, Jack Blanchard, Holly Sharp, Lee Taylor, Matthew R. Kuennen, and Ben J. Lee. 2020. "Addition of Pectin-alginate to a Carbohydrate Beverage Does Not Maintain Gastrointestinal Barrier Function During Exercise in Hot-humid Conditions Better Than Carbohydrate Ingestion Alone". Loughborough University. https://hdl.handle.net/2134/13234892.v1. 
Addition of pectin-alginate to a carbohydrate beverage does not maintain gastrointestinal barrier function during exercise in hot-humid conditions better than carbohydrate ingestion alone.

Tessa R Flood ${ }^{1 *}$, Stefano Montanari ${ }^{1 *}$, Marley Wicks ${ }^{1}$, Jack Blanchard ${ }^{1}$, Holly Sharp ${ }^{1}$, Lee Taylor ${ }^{2,3,4}$, Matthew R Kuennen ${ }^{5}$, Ben J Lee ${ }^{1,6}$

*joint first authors

\section{Author Affiliations:}

${ }^{1}$ Institute of Sport, Occupational Performance Research Group, University of Chichester, UK ${ }^{2}$ Loughborough University, School of Sport, Exercise and Health Sciences, Loughborough, UK.

${ }^{3}$ University of Technology Sydney (UTS), Sport \& Exercise Discipline Group, Faculty of Health, Australia.

${ }^{4}$ University of Technology Sydney (UTS), Human Performance Research Centre, Australia.

${ }^{5}$ Department of Exercise Science, High Point University, High Point, North Carolina, USA

${ }^{6}$ Centre for Sport, Exercise and Life Sciences, Coventry University, Coventry, CV15FB, UK

\section{Contact Information for Corresponding Author:}

Dr Ben J Lee

Institute of Sport

Occupational Performance Research Group

University of Chichester

Chichester, West Sussex, PO10 6PE

Phone: +44 (0)1243 816127

Email: BenLee1984.bl@googlemail.com

\section{Contact Information for Other Authors:}

Name: Tessa R. Flood

Name: Stefano Montanari

Name: Marley Wicks

Name: Jack Blanchard

Name: Holly Sharpe

Name: Lee Taylor

Name: Matthew R. Kuennen
Email: T.Flood@chi.ac.uk

Email: SMontan1@stu.chi.ac.uk

Email: Marley_wicks1997@hotmail.co.uk

Email: Jack.blanchard96@yahoo.com

Email: hollysharp4@gmail.com

Email: 1.taylor2@lboro.ac.uk

Email: mkuennen@highpoint.edu 


\section{Abstract}

Purpose: To compare the effects of consuming a $16 \%$ maltodextrin+fructose+pectin alginate (MAL+FRU+PEC+ALG) drink against a nutrient matched maltodextrin-fructose (MAL+FRU) drink on enterocyte damage and gastrointestinal permeability after cycling in hot and humid conditions. Methods: Fourteen recreational cyclists (7 men) completed three experimental trials in a randomized placebo controlled design. Participants cycled for $90 \mathrm{~min}$ $\left(45 \% \mathrm{VO}_{2 \max }\right)$ and completed a 15 min time-trial in hot $\left(32^{\circ} \mathrm{C}\right)$ humid $(70 \%$ relative humidity) conditions. Every 15-minutes cyclists consumed $143 \mathrm{~mL}$ of either (1) water; (2) MAL+FRU+PEC+ALG (90g CHO'hr/16\% w/v), (3) - a ratio-matched MAL+FRU drink also $(90 \mathrm{~g} \mathrm{CHO} \cdot \mathrm{hr} / 16 \% \mathrm{w} / \mathrm{v})$. Blood was sampled before and after exercise and gastrointestinal (GI) permeability determined by serum measurements of intestinal fatty acid binding protein (IFABP) and the percent ratio of lactulose (5g) to rhamnose (2g) recovered in post-exercise urine. Results: Compared to WATER, IFABP decreased by $349 \pm 67 \mathrm{pg} \mathrm{mL}^{-1}$ with MAL+FRU+PEC+ALG ( $\mathrm{p}=0.007)$, and by $427 \pm 56 \mathrm{pg} \cdot \mathrm{mL}^{-1}$ with MAL+FRU ( $\left.\mathrm{p}=0.02\right)$. GI permeability was reduced in both the MAL+FRU+PEC+ALG (by $0.019 \pm 0.01, \mathrm{p}=0.0003$ ) and MAL+FRU (by 0.014 $\pm 0.01, \mathrm{p}=0.002$ ) conditions relative to WATER. Conclusion. Both CHO beverages attenuated GI barrier damage to a similar extent relative to water. No metabolic, cardiovascular, thermoregulatory or performance differences were observed between the $\mathrm{CHO}$ beverages.

\section{Novelty bullets}

- Consumption of multiple-transportable $\mathrm{CHO}$, with or without hydrogel properties, preserves GI barrier integrity and reduces enterocyte damage during prolonged cycling in hot-humid conditions. 


\section{Keywords}

Alginate, hydrogel, carbohydrate, cycling, heat, IFABP, Gastrointestinal symptoms

\section{INTRODUCTION}

Carbohydrate $(\mathrm{CHO})$ supplements with an appropriate composition and administration regimen can have large benefits on endurance performance (Vandenbogaerde and Hopkins 2011). Present guidelines recommend that multiple transportable CHOs such as glucose/maltodextrin and fructose should be ingested at rates of $80-144 \mathrm{ghr}^{1}$ to increase exogenous CHO oxidation and reduce gastrointestinal (GI) discomfort (Rowlands et al. 2015). However, there is some evidence that larger doses of multiple transportable CHO (>90 $\left.\mathrm{g} \cdot \mathrm{hr}^{-1}\right)$ may exceed GI absorption capacity and contribute to the development of GI symptoms (de Oliveira and Burini 2014), which in severe cases can precipitate complete withdrawal from an athletic event (Costa et al. 2017).

Innovations in $\mathrm{CHO}$ provision have seen the addition of pectin and sodium-alginate to traditional multiple transportable $\mathrm{CHO}$ beverages. Upon exposure to the low $\mathrm{pH}$ environment of the stomach the pectin-alginate polysaccharides encapsulate $\mathrm{CHO}$ within a hydrogel, which theoretically allows for $\mathrm{CHO}$ passage into the duodenum without activation of glucose receptors (Sutehall et al. 2018). It has been speculated that hydrogel formulations increase gastric emptying rates during exercise, enhance absorption of oxidizable $\mathrm{CHO}$, reduce the incidence and severity of gastrointestinal symptoms, and allow provision of $\mathrm{CHO}$ in concentrations that far exceed what can typically be tolerated using commercially available sports drinks (Sutehall et al. 2018). However, when pectin-alginate CHO drinks have been compared to traditional glucose(polymer) beverages, no differences have been shown in whole body substrate oxidation, blood glucose availability, or GI symptoms during either 90 or 180 
minutes of treadmill running at $60 \% \mathrm{VO}_{2} \max$ (McCubbin et al. 2019; Barber et al. 2020; both $\left.90 \mathrm{~g} \cdot \mathrm{hr}^{-1} \mathrm{CHO}, 16 \% \mathrm{w} / \mathrm{v}\right), 120$ minutes of cycling at 55\% $W_{\max }$, (Mears et al. 2020, 80g $\mathrm{hr}^{-1}, 14 \%$ w/v), 98 minutes of variable-intensity cycling (Baur et al., 2019, 78g hr ${ }^{-1}, 8 \% \mathrm{w} / \mathrm{v}$ ) or 120

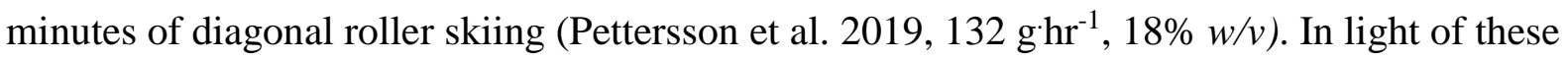
findings, it is not surprising that there is no empirical evidence to support additional ergogenic benefits beyond those that are already associated with the ingestion of traditional glucose(polymer)-fructose mixtures during running (McCubbin et al. 2019; Barber et al. 2020) and cycling exercise (Baur et al., 2019, Mears et al., 2020). It is possible that hydrogel formulations are only ergogenic in certain contexts, such as conditions that are associated with greater GI disturbance or alterations in $\mathrm{CHO}$ metabolism.

The combination of exercise and heat stress result in major alterations in $\mathrm{CHO}$ metabolism. Increased ambient temperature increases $\mathrm{CHO}$ oxidation during exercise, which results in increased muscle glycogen use (Febbraio et al. 1994) but no change in glucose uptake by the muscle (Jentjens et al. 2002). Prolonged endurance exercise in hot conditions reduces splanchnic blood flow and increases intestinal ischemia (Rowell et al. 1968), which can lead to GI barrier dysfunction, increased GI barrier permeability and/or enterocyte damage (Lambert et al., 2008), factors believed to increase the risk of exertional heat illness. Splanchnic hypoperfusion has also suggested to be a major pathophysiological process that increases the risk of gastrointestinal symptoms during exercise (Jeukendrup et al. 2000). Exercise in the heat could therefore be one context where pectin-alginate could theoretically be superior to traditional multi-transportable $\mathrm{CHO}$ beverages. At present there is no experimental data to support or refute this hypothesis. Data that examine whether the ingestion of CHO-hydrogels and more traditional glucose(polymer)-fructose beverages preserve GI barrier permeability and intestinal barrier damage are also currently lacking. 
Therefore, the primary aim of the present study was to compare small intestine barrier permeability (lactulose-rhamnose ratio) and intestinal barrier damage (IFABP) following the ingestion of either water, a $16 \% w / v$ maltodextrin-fructose-pectin-alginate drink, or a traditional maltodextrin+fructose drink during 90-minutes of submaximal cycling in hot-humid conditions. Substrate oxidation rates, blood glucose availability, blood lactate responses, subjective ratings of GI discomfort, and time trial performance were also examined. We hypothesized that ingestion of multiple transportable $\mathrm{CHO}$ would prevent excessive GI permeability and reduce enterocyte damage as compared to water alone. In light of previous experiments reporting similar incidence and severity of GI symptoms between hydrogel and nutrient matched placebo beverages, we hypothesised that no further benefit would be provided by the addition of pectin-alginate to the maltodextrin-fructose mixture.

\section{MATERIALS AND METHODS}

\section{Participants}

Seven men (age $27 \pm 8$ years; height $1.77 \pm 0.09 \mathrm{~m}$, mass $74.1 \pm 11.4 \mathrm{~kg}$; maximal aerobic capacity $56.4 \pm 7.6 \mathrm{~mL} \mathrm{~kg}^{-1} \mathrm{~min}^{-1}$; peak power output, $328 \pm 30$ Watts), and seven women (age $23 \pm 2$ years; height $1.67 \pm 0.08 \mathrm{~m}$, mass $67.4 \pm 8.2 \mathrm{~kg}$; maximal aerobic capacity $54.3 \pm 12.3$ $\mathrm{mL} \cdot \mathrm{kg}^{-1} \mathrm{~min}^{-1}$; peak power output, $279 \pm 32$ Watts) volunteered to participate in this study, which was approved by the University of Chichester Institutional Review Board. Participants were required to be recreational endurance athletes, with a $\mathrm{VO}_{2} \mathrm{max}$ above $50 \mathrm{ml} \mathrm{kg}^{-1} \mathrm{~min}^{-1}$ (men) or $45 \mathrm{ml} \mathrm{kg}^{-1} \mathrm{~min}^{-1}$ (women). All were accustomed to consuming $\mathrm{CHO}(30-60 \mathrm{~g} / \mathrm{hr}$ ) during competition, but no participant was accustomed to consuming $\mathrm{CHO}$ at higher rates (90 g.hr). Before participation, each subject attended a meeting informing them of the purpose of the experiment. During this visit, participants were screened for contraindications to exercise 
and were fully informed of the risks associated with all procedures. All participants provided written informed consent prior to participation in the study.

\section{Experimental design}

The study design was a randomised, double blind, control trial in which the effects of the ingestion of an encapsulated glucose (maltodextrin)-fructose hydrogel solution (MAL+FRU+PEC+ALG) on metabolic and performance outcomes were compared against a nutrient matched maltodextrin-fructose (MAL+FRU) solution that did not contain pectinalginate, or water (WATER) alone. Randomization was performed by B.J.L. using free online software (https://www.randomizer.org).

Each participant made 5 visits to the laboratory, and each visit was separated by at least 5 days. The first visit consisted of an incremental test to exhaustion where $\mathrm{VO}_{2 \max }$ and peak power output were established. This was followed by a familiarisation ride that mimicked the performance test but was performed under thermoneutral conditions. The second visit consisted of another familiarization ride under thermoneutral conditions. This was used to establish the within-study coefficient of variation for time-trial performance test ( $<4 \%$ for this experiment). The third, fourth, and fifth visits consisted of the same exercise protocol, but performed under hot $\left(32^{\circ} \mathrm{C}\right)$, humid $(70 \% \mathrm{RH})$ conditions. Participants were provided with either flavoured sugar-free water (WATER), a $16 \% \mathrm{w} / \mathrm{v}$ MAL+FRU+PEC+ALG drink mixture, or a $16 \% \mathrm{w} / \mathrm{v}$ MAL+FRU drink mixture. To achieve blinding, drinks were made by the principle investigator and left in the environmental chamber for approximately 90 minutes prior to each trial, without further communication with those completing data collection. All laboratory tests were performed at the same time of day, starting from 12:00-14:00. Female participants were taking 
a monophasic oral contraceptive, and performed their exertional heat stress trials during the 3 weeks of stable hormone intake.

\section{Standardization of diet and physical activity}

To standardise diet and pre-trial activity, participants were asked to prepare for each session as though they were preparing for a competitive race, and then replicate these procedures before all visits. Specifically, participants were asked to refrain from strenuous exercise and alcohol, and record their food and fluid intake for 24 hours before each trial. They were also not taking any medications (e.g., nonsteroidal anti-inflammatory drugs, antidepressants, or diuretics) or nutritional supplements (bovine colostrum, curcumin, dietary nitrate, glutamine, 1-citrulline, 1arginine, probiotics, or quercetin) that might influence GI barrier function. Participants were asked to continue to avoid the use of these products while enrolled in the study. On each trial day, participants were instructed to eat a self-selected $\mathrm{CHO}$ rich meal and drink $12 \mathrm{~mL} \mathrm{~kg}$ of water 3 hours before their laboratory visit. Participants were provided with a photo copy of their diet intake from their first experimental visit and asked to replicate their pre-trial routine for all subsequent visits. Participants were reminded of these restrictions 48 hours before each experiment and adherence confirmed verbally with each individual before each trial.

\section{Preliminary assessment and familiarization}

Upon arrival to the laboratory the body mass and height of each subjects were determined with an electronic scale (Seca Ltd Birmingham, UK) and stadiometer (Harpenden Stadiometer, Holtain LTD, Pembrokeshire, Wales). After this subjects completed a submaximal and maximal exercise test on an electronically braked cycle ergometer (Excalibur Sport, Lode, Groningen, The Netherlands) (described in Cramer and Jay 2014). Indirect calorimetry data $\left(\mathrm{O}_{2}\right.$ uptake, $\mathrm{CO}_{2}$ production, and minute ventilation) were collected into 200 litre Douglas bags 
during the last 45 seconds of each stage and after a 60 second equilibration period. Concurrently, ambient $\mathrm{O}_{2}$ and $\mathrm{CO}_{2}$ concentrations were measured and all calculations adjusted to incorporate the measured inspired oxygen and carbon dioxide fractions obtained during each collection period (Betts and Thompson, 2012). After a short rest-recovery period $(<15$ minutes), participants completed the first of two familiarization sessions that were intended to reduce learning and training effects during the subsequent 15-minute time-trial. Familiarization sessions were conducted in an air-conditioned laboratory $\left(21^{\circ} \mathrm{C}, 40 \% \mathrm{RH}\right)$ and consisted of 90 minutes' steady state cycling at $45 \% \mathrm{VO}_{2}$ peak, which was followed by a short break $(<5$ minutes) and a 15-min time trial. With the exception of CHO provision and differences in the ambient environment, all procedures during both familiarization sessions were identical to those undertaken during the main experimental trials.

\section{Experimental trials}

The experimental procedure is shown in Figure 1. All testing was conducted in afternoon hours (between 12:00 and 15:00) and all trials for an individual participant were conducted at the same time of day ( \pm 1 hour). This schedule was intended to minimise the effects of circadian variation on performance and thermoregulatory variables. Each participant was given a calibrated temperature pill (CorTemp, HQ Inc, USA) to ingest the night before their experimental trial. Upon arrival to the laboratory, participants provided a urine sample for assessment of hydration status via urine specific gravity (USG; ATAGO 2791, ATAGO, Tokyo, Japan) and urine osmolality (USMO; Osmocheck PAL-OSMO; Vitech Scientific, Partridge Green, West Sussex, UK). Participants were considered euhydrated if USG was < 1.020 and USMO was $<650 \mathrm{mOsmo} \mathrm{L}^{-1}$. Participants weighed themselves nude on a precision platform balance (accurate to $0.01 \mathrm{~kg}$ ), after which they were fitted with a HR monitor and skin thermistors (Grant Instruments, Shepreth, UK) on the left hand and right scapula, neck and shin 
according to ISO 13732-3:2005. Following a 20-minute resting equilibration period, a 10-ml blood was collected without stasis and controlling for arm position and participants entered the climate chamber set at $32^{\circ} \mathrm{C}, 70 \%$ relative humidity (Wet bulb globe temperature, WBGT $=$ $31.3{ }^{\circ} \mathrm{C}$ ). They sat for an additional $15 \mathrm{~min}$ to equilibrate to the testing conditions. After the equilibration period participants moved to the cycle ergometer and cycled at a work rate equivalent to $45 \% \mathrm{VO}_{2}$ peak $(110 \pm 21 \mathrm{~W})$ against an air velocity of 2 meters per second (the maximum velocity our chamber fans produce). Heart rate, deep body temperature $\left(\mathrm{T}_{\mathrm{pill}}\right)$, and skin temperature $\left(\mathrm{T}_{\text {skin }}\right)$ were logged continuously throughout exercise and manually recorded at 10 minute intervals. Skin and deep body temperature date were later used to calculate weighted mean skin temperature and mean body temperatures via standardized equations (ISO 13732-3:2005; Kenny, 1998). The physiological strain index (PSI) was calculated from changes in deep body temperature and HR during exercise (Moran et al. 1998). Oxygen consumption and carbon dioxide production were recorded using indirect calorimetry over a 2minute collection period (1-minute equilibration, 1-minute collection) at the end of each 10minute interval, and all calculations adjusted for ambient $\mathrm{O}_{2}$ and $\mathrm{CO}_{2}$ fractions measured concurrently. Standard stoichiometric equations (that assume negligible protein oxidation during exercise) were used to calculate oxidation rates $\left(\mathrm{g} \cdot \mathrm{min}^{-1}\right)$ for $\mathrm{CHO}$ and fat (FAT) (Frayn 1983). Fingertip capillary blood samples were collected into ethylenediaminetetraacetic acid (EDTA) containing microtubes (Sarsetdt, Leicester, UK) at rest and immediately after each drink consumption throughout the exercise period for later determination of whole blood lactate and glucose (YSI STAT 2300, Yellow Springs Instruments, Ohio, USA), the procedures for which are described below.

[Please insert Figure 1 near here]

\section{Carbohydrate drinks}


During the first 3 minutes of exercise participants drank an initial bolus $(250 \mathrm{~mL})$ of one of the three experimental drinks (WATER, MAL+FRU, MAL+FRU+PEC+ALG). Thereafter, a drink volume of $\sim 143 \mathrm{~mL}$ was provided at 15 minute intervals. Total fluid provided during the protocol was $\sim 1.172$ litres in each of the three experimental conditions. All drinks contained 1 g sodium chloride $\cdot \mathrm{L}^{-1}$ and each $\mathrm{CHO}$ drink provided an average intake of $1.5 \mathrm{~g} \mathrm{CHO} \mathrm{min}^{-1}$,

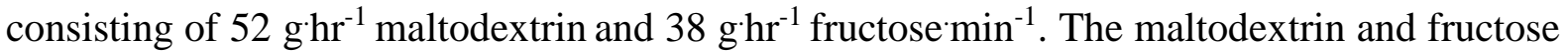
content of each $\mathrm{CHO}$ beverage was dictated by the composition of the commercially available product that was used throughout testing (Maurten Drink Mix 320, Maurten, Gothenburg, Sweden). Participants were not advised of the contents of the MAL+FRU and MAL+FRU+PEC+ALG solutions; however, the WATER solution was not blinded due to difficulty in matching the 'flavourless' sweet flavouring of the $\mathrm{CHO}$ beverages.

\section{Performance test}

A final $143 \mathrm{~mL}$ bolus of the test drink was provided at the end of the 90 -minute exercise bout and a $10 \mathrm{~mL}$ blood sample was collected as previously described. At this point the cycle ergometer was switched to the linear mode for time-trial testing, where the linear factor was individualized to elicit a $50 \% \mathrm{VO}_{2}$ peak power output for each participant at a cadence of 60 rpm (Kenefick et al. 2010). Selection of a linear factor that would elicit 50\% $\mathrm{VO}_{2}$ peak at 60 rpm provided ample room for self-paced improvement up to maximal sustainable workloads, which were estimated at $100 \mathrm{rpm}$ from $\mathrm{VO}_{2}$ peak testing and expected to occur during the 15min performance time trial. Pedal cadence and workload were blinded, so that only elapsed time was known during the time trial, and no external motivation was provided. Elapsed time was given at standardized times $(5: 00,10: 00,12: 00,13: 00,14: 00,14: 30$, and 14:50 mm:ss). To limit distractions $\mathrm{HR}$ and $\mathrm{T}_{\text {pill, }}$, were measured remotely every minute during exercise and a final capillary sample was collected 5 minutes after TT completion. 


\section{Questionnaires.}

Subjective ratings of perceived exertion (Borg 1982), thermal sensation (Tikuisis et al. 2002) and thermal comfort (ASHRAE 2004) were collected at rest and at 10 minute intervals throughout exercise. At $30 \mathrm{~min}$ intervals participants were asked to fill out a short questionnaire regarding the presence of GI problems at that moment (Gaskell et al. 2019).

\section{Intestinal damage}

Venous whole blood samples were aliquoted into either heparinized tubes (Sarstedt, Leicester, UK) or tubes that contained a clot activator (Sarstedt, Leicester, UK). Heparinized tubes were used for haematocrit and haemoglobin assessment, after which these values were used to calculate the percent change in plasma volume according to the equation of Dill and Costill (Dill \& Costill, 1974). Clot activator tubes were allowed to clot on the benchtop for 20 minutes, after which they were then spun at $1500 \mathrm{~g}$ for 10 minutes. Serum was aliquoted into microeppendorf tubes, and stored $\left(-80^{\circ} \mathrm{C}\right)$ until later batch analysis. Serum intestinal fatty acid binding protein (I-FABP) concentrations were measured as a marker of intestinal damage using a commercially available ELISA sensitive to $4.7 \mathrm{pg} \cdot \mathrm{mL}^{-1}$ (Hycult Biotech, USA).

\section{Analysis of urine samples}

Assessment of intestinal permeability was quantified on the basis of absorption and urinary excretion of a $50 \mathrm{ml}$ solution containing $2 \mathrm{~g}$ rhamnose and $5 \mathrm{~g}$ lactulose. Rhamnose is a small molecule $(182.2 \mathrm{~g} / \mathrm{mol})$ that is passively absorbed through the small intestine via transcellular transport, whereas lactulose is a larger molecule $(342.3 \mathrm{~g} / \mathrm{mol})$ that can only be passively absorbed via paracellular transport (i.e. via alterations in the integrity of the tight junction proteins) (Bjarnason, Macpherson, \& Hollander, 1995; Maxton et al., 1986). These ingested 
sugar probes are not extensively metabolized by the human body, allowing for their eventual excretion in urine in an unchanged format that is proportional to the quantity of each sugar absorbed. An increase in the ratio of lactulose to rhamnose in urine collected during the $3 \mathrm{hr}$ window following exercise is indicative of an increase in small bowel permeability (Maxton et al. 1986; Bjarnason et al. 1995). Lactulose was quantified with an EIA (K-LACT, Megazyme), with some deviations from the manufacturer's instructions.

The supplied glucose/fructose $(0.2 \mathrm{mg} / \mathrm{ml})$ standard was serially diluted 1:2. Fifty-five microliters of blank, standard, or urine were added to 96-well microtiter plates, followed by 55 $\mu 1$ of TAE buffer ( $\mathrm{pH} 7.6), 10 \mu \mathrm{l}$ of $\beta$-galactosidase, $10 \mu$ limidizole buffer, and $10 \mu \mathrm{l}-$ NAD+/ATP solution. The plate was mixed and incubated for 3 min at $37^{\circ} \mathrm{C}$, then read at 340 $\mathrm{nm}$ (A1). The plate was next incubated at $37^{\circ} \mathrm{C}$ for $2 \mathrm{~h}$ to allow -galactosidase conversion of lactulose into free glucose and fructose. After incubation hexokinase +G-6-P dehydrogenase solution was diluted 1:5 in TAE buffer, and $10 \mu \mathrm{l}$ was added to all occupied wells. The plate was mixed and incubated for $5 \mathrm{~min}$ at $37^{\circ} \mathrm{C}$, then read at $340 \mathrm{~nm}$ (A2). PGI was diluted 1:5 in $0.5 \mathrm{X}$ TAE buffer, and $10 \mu 1$ was added to the plate, mixed, and incubated at $37^{\circ} \mathrm{C}(5 \mathrm{~min})$ before a final reading at and read at $340 \mathrm{~nm}(\mathrm{~A} 3)$. Lactulose $=(\mathrm{A} 3-\mathrm{A} 2)-\mathrm{A} 1$. Rhamnose was quantified using a colourmetric assay (K-Rhamnose, Megazyme, Dublin, Ireland) according to the manufacturer instructions.

\section{Statistical analysis}

Statistical analysis was performed using IBM SPSS for Windows (Version 25, SPSS, Chicago, Illinois). Unless stated otherwise, data in text, tables, and figures are presented as mean \pm SD. For clarity of presentation, graphical data are presented with mean trial data offset and unidirectional error bars. Individual data points are displayed for all major outcome variables. 
The main comparisons of interest were between the two $\mathrm{CHO}$ beverages, with the water trial serving as a control to evaluate the effects of providing nutrition, or not, on markers of gastrointestinal damage and permeability. Performance was measured as the total work performed $(\mathrm{kJ})$ during the 15-minute time trial. A power analysis [performed a-priori and with conventional alpha (0.05) and beta (0.20) values] indicated that eight participants would be sufficient to detect a meaningful (> 5\%) change in time trial performance (Lipsey, 1990). This estimate was made using both our own previous experience with this performance test, and data published by others (Kenefick et al. 2010). Post-hoc analysis of the familiarization data confirmed our estimations, indicating a within-subject variability of $<4 \%$ for our cohort. Differences in dietary intake, ambient conditions, urine specific gravity, urine osmolality, fluid intake and sweat rate were determined using one-way ANOVAs with Tukey HSD post hoc tests. Differences in cardiovascular, thermoregulatory, and respiratory/substrate oxidation measurements, and plasma metabolites were determined using mixed linear models, where trial (WATER, MAL+FRU+PEC+ALG, MAL+FRU) and time served as fixed effects. Differences in serum I-FABP were determined using mixed linear models, where trial and time (pre and post exercise) served as fixed effects. For all statistical tests, significant main effects $(\mathrm{p}<0.05)$ were explored with Tukey HSD post hoc procedure. Differences in gastrointestinal symptoms were determined using Friedman's test, and main effects explored using Dunn's test. To control for the false discovery rate and the effects of multiplicity during multiple comparisons, the procedures of Benjamini and Hochberg (1995) were followed after all post hoc procedures (Benjamini \& Hochberg, 1995) and precise $p$-values are reported where relevant.

\section{RESULTS}


Equality of study conditions. There was no difference in ambient temperature, relative humidity, body mass, or hydration status, between study conditions (Supplementary Table S1).

\section{Cardiovascular and thermoregulatory responses}

Data and mixed effects model interactions for selected physiological variables are provided in Table 1. Between-condition differences were noted for RER, which was higher in both CHO trials relative to WATER $(\mathrm{p}<0.001)$. No other differences for oxygen consumption, carbon dioxide production, heart rate, deep body temperature, mean skin temperature, mean body temperature, physiological strain index, RPE, and TS and TC were observed between the different drink conditions.

[please insert Table 1 near here]

\section{Time trial performance}

Figure 2 displays the individual work completed in each exercise condition. Average power outputs during the TT were $168 \mathrm{~W}$ (95\% CI: 138-199 W) in WATER, $192 \mathrm{~W}$ (95\% CI: 162 to $222 \mathrm{~W}$ ) in MAL+FRU+ALG+PEC, and $190 \mathrm{~W}$ (95\% CI: 163 to $217 \mathrm{~W}$ ) in MAL+FRU. There was a main effect of study condition for total work completed during the 15 -minute time trial $[\mathrm{F}(1.422,18.13)=18.48, \mathrm{p}=0.0002)]$. Post hoc analysis indicated that work output was greater in MAL+FRU+PEC+ALG [by $21.7 \mathrm{~kJ}(95 \% \mathrm{CI}: 10.2$ to $33.3 \mathrm{~kJ}), \mathrm{p}=0.0007$ ] and MAL+FRU [by $19.1 \mathrm{~kJ}$ (95\% CI: 6.1 to $32.0 \mathrm{~kJ}), \mathrm{p}=0.005$ ] as compared to WATER. No difference in work output was shown between MAL+FRU+PEC+ALG and MAL+FRU ( $p=0.551)$.

[please insert Fig 2 near here] 
Intestinal fatty acid binding protein. Data are presented for $\mathrm{n}=13$ due to difficulty in consistently obtaining a venous blood sample from one participant. There was an interaction between study condition and measurement time for absolute IFABP concentrations [F (1.915, $22.98)=14.57, \mathrm{p}<0.0001]$. As shown in Figure 3A, IFABP concentrations were elevated above resting values following exercise in the WATER condition $(\mathrm{p}=0.0004)$, but were not increased following exercise in the MAL+FRU+PEC+ALG $(\mathrm{p}=0.091)$ or MAL+FRU (0.502) conditions. Post hoc analysis indicated that IFABP concentrations at the end of exercise were greater in WATER compared to MAL+FRU+PEC+ALG [by $349 \mathrm{pg} \cdot \mathrm{mL}^{-1}$ (95\% CI: 137 to 561 $\left.\left.\left.\mathrm{pg} \cdot \mathrm{mL}^{-1}\right) ; \mathrm{p}=0.007\right)\right]$ and MAL+FRU [by $427\left(95 \% \mathrm{CI}: 152\right.$ to $\left.\left.701 \mathrm{pg} \cdot \mathrm{mL}^{-1}\right), \mathrm{p}=0.018\right)$ ]. No differences in post exercise IFABP concentration were shown between MAL+FRU+PEC+ALG and MAL+FRU $(p=0.90)$.

Small intestine permeability. Data are presented for $\mathrm{n}=12$ because neither sugar was consistently detectable within the urine samples of two participants. There was a main effect for exercise condition on $\mathrm{L}: \mathrm{R}$ ratio $[\mathrm{F}(1.669,18.36)=23.95, \mathrm{p}<0.0001]$. As shown in Figure 3B, L:R ratio was greatest in WATER, and lower in both MAL+FRU+PEC+ALG [by 0.019 (95\% CI: 0.010 to 0.027$), \mathrm{p}=0.0003$ ], and MAL+FRU [by 0.014 (95\% CI: 0.006 to 0.022$), \mathrm{p}$ $=0.0018]$. No differences in L:R were found between MAL+FRU+PEC+ALG and MAL+FRU $(\mathrm{p}=0.083)$.

[please insert Fig 3 near here]

Gastrointestinal symptoms. GI symptoms and Friedman's test results are presented in Table 2. There was no difference in total GI symptoms between exercise conditions $(p=0.156)$. Overall gut discomfort was greater in MAL+FRU+PEC+ALG compared to WATER ( $p=0.0007)$, but 
no difference between WATER and MAL +FRU $(\mathrm{p}=0.07)$ was observed. Overall gut fullness was higher in MAL+FRU+PEC+ALG $(\mathrm{p}=0.0007)$ and MAL+FRU $(\mathrm{p}=0.002)$ compared to WATER. Main effects were also observed for belching $(p=0.024)$ and bloating $(p=0.035)$, however, with post hoc adjustment the differences between trials for belching and bloating become less clear (both $\mathrm{p}>0.05$ ).

[please insert Table 2 near here]

\section{Substrate utilization and plasma metabolites}

Whole body carbohydrate oxidation rate. There was an interaction between study condition and exercise time for $\mathrm{CHO}$ oxidation $[\mathrm{F}(5.267,53.00)=5.248, \mathrm{p}=0.0005]$. As shown in Figure 4A, post hoc analysis indicated that $\mathrm{CHO}$ oxidation was increased from 40 minutes through the end of exercise in both MAL+FRU+PEC+ALG and MAL+FRU (as compared to WATER, all $\mathrm{p}<0.01)$. No differences in $\mathrm{CHO}$ oxidation rate were shown between MAL+FRU+PEC+ALG and MAL+FRU (all p > 0.05). On average, $\mathrm{CHO}$ oxidation was 0.38 $\mathrm{g} \cdot \mathrm{min}^{-1}\left(95 \% \mathrm{CI}: 0.30\right.$ to $\left.0.46 \mathrm{~g} \cdot \mathrm{min}^{-1}\right)$ and $0.34 \mathrm{~g} \cdot \mathrm{min}^{-1}\left(95 \% \mathrm{CI} 0.23\right.$ to $\left.0.45 \mathrm{~g} \cdot \mathrm{min}^{-1}\right)$ greater in the MAL+FRU+PEC+ALG and MAL+FRU trials when compared to WATER.

Whole body fat oxidation rate. There was an interaction between study condition and exercise time for FAT oxidation $[\mathrm{F}(4.492,43.23)=5.264, \mathrm{p}=0.0009]$. As shown in Figure 4B, post hoc analysis indicated that FAT oxidation was lower from 50 minutes through the end of exercise in both MAL+FRU+PEC+ALG and MAL+FRU (as compared to WATER, all $\mathrm{p}<$ 0.01). No differences in FAT oxidation rate were shown between MAL+FRU+PEC+ALG and 
MAL+FRU (all $\mathrm{p}>0.05$ ). On average FAT oxidation was reduced by $0.17 \mathrm{~g} \cdot \mathrm{min}^{-1}$ (95\% CI:

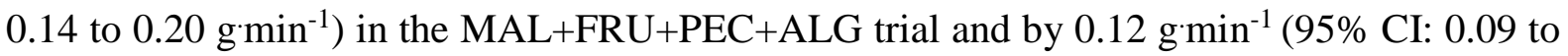

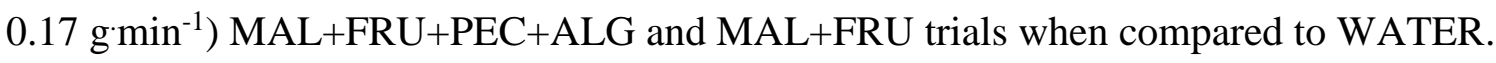

Blood glucose. There was an interaction between study condition and exercise time for blood glucose $[\mathrm{F}(5.282,68.66)=9.886, \mathrm{p}<0.0001]$. As shown in Figure $4 \mathrm{C}$, post hoc analysis indicated that blood glucose concentrations were increased from 15 minutes of exercise through the end of the time trial period in both MAL+FRU+PEC+ALG and MAL+FRU (as compared to WATER, $\mathrm{p}<0.0001$ at all-time points). On average, blood glucose was 1.20 $\mathrm{mmol} \cdot \mathrm{L}^{-1}\left(95 \% \mathrm{CI}: 1.01\right.$ to $\left.1.40 \mathrm{mmol} \mathrm{L}^{-1}\right)$ greater in $\mathrm{MAL}+\mathrm{FRU}+\mathrm{PEC}+\mathrm{ALG}$ and $1.15 \mathrm{mmol} \mathrm{L}^{-}$ ${ }^{1}$ (95\% CI: 0.96 to $1.33 \mathrm{mmol} \mathrm{L}^{-1}$ ) greater in MAL+FRU, as compared to WATER. No differences in blood glucose concentration were shown between MAL+FRU+PEC+ALG and MALT+FRUC (all p > 0.05).

Blood lactate. There was an interaction between study condition and exercise time for blood lactate $[\mathrm{F}(3.487,45.33)=10.27, \mathrm{p}<0.0001]$. As shown in Figure 4D, post hoc analysis indicated that blood lactate concentrations were increased from 30 minutes of exercise through the end of the time trial period in both MAL+FRU+PEC+ALG and MAL+FRU (as compared to WATER, $\mathrm{p}<0.0001$ at all-time points). On average, blood lactate was $0.44 \mathrm{mmol} \mathrm{L}^{-1}(95 \%$ CI: 0.31 to $\left.0.59 \mathrm{mmol} \mathrm{L}^{-1}\right)$ greater in MAL+FRU+PEC+ALG and $0.40 \mathrm{mmol} \cdot \mathrm{L}^{-1}(95 \% \mathrm{CI}: 0.26$ to $0.55 \mathrm{mmol} \mathrm{L}^{-1}$ ) greater in MAL +FRU compared to WATER. No differences in blood lactate concentration were shown between MAL+FRU+PEC+ALG and MAL +FRU (all p > 0.05). Following the 15 minute time trial, blood lactate concentrations were further elevated as a result of the best effort work rate, with concentrations greater in both the MAL+FRU+PEC+ALG 
$\left(5.50 \pm 2.06 \mathrm{mmol} \cdot \mathrm{L}^{-1}\right)$ and MAL $+\mathrm{FRU}\left(5.22 \pm 1.94 \mathrm{mmol} \cdot \mathrm{L}^{-1}\right)$ trial compared to WATER $\left(3.95 \pm 2.06 \mathrm{mmol} \cdot \mathrm{L}^{-1}\right)(\mathrm{p}<0.0001)$.

[please insert Fig 4 near here]

\section{DISCUSSION}

This study investigated whether the addition of pectin-alginate to a standard matched concentration multiple-transportable $\mathrm{CHO}$ beverage would better preserve GI barrier function and improve metabolic and performance responses during cycling exercise under hot and humid conditions. In support of our primary hypothesis, the MAL+FRU+PEC+ALG and MAL+FRU drink both attenuated the appearance of circulating IFABP, a marker of enterocyte damage, and prevented excessive GI barrier permeability, as indicated by reductions in the lactulose:rhamnose ratio when compared to water ingestion alone. However, the addition of pectin-alginate provided no additional benefit on either marker of GI barrier function beyond multiple transportable $\mathrm{CHO}$ ingestion alone. Taken together, these data suggest that GI integrity can be preserved during cycling exercise in conditions of high heat and humidity with regular ingestion of multiple transportable $\mathrm{CHO}$ at a rate of $\sim 90 \mathrm{~g}^{\mathrm{hr}}{ }^{-1}$. Consumption of both MAL+FRU+PEC+ALG and non-gelling MAL+FRU beverage improved time trial performance (each by $\sim 17 \%$ ) relative to water intake alone, despite an increase in subjective GI symptoms relative to water.

The addition of a novel blend of alginate and pectin to sports drinks is proposed to form a hydrogel upon contact with stomach acid, encapsulating the $\mathrm{CHO}$ and enhancing gastric emptying rates to facilitate higher $\mathrm{CHO}$ oxidation rates during exercise (Sutehall, 2018). Our data do not support this proposition. Instead, they support previous observations made in thermoneutral environments during running (McCubbin et al. 2019; Barber et al. 2020) and 
cycling (Baur et al. 2019; Mears et al. 2020a), which reported no differences in blood glucose concentrations, substrate oxidation, or exercise performance between the two drink mixtures. While we did not measure gastric emptying in the present investigation, the lack of observable differences in blood glucose concentrations and $\mathrm{CHO}$ oxidation rates in both $\mathrm{CHO}$ trials suggest that neither gastric emptying nor intestinal absorption were altered by the addition of pectin and alginate.

In the present study we observed evidence of enterocyte injury and increased small intestine permeability when water alone was ingested during exercise (i.e., up to $556 \mathrm{pg} \cdot \mathrm{mL}^{-1}$ increase in serum IFABP concentration). The magnitude of post-exercise IFABP concentrations were reduced (in 12/13 participants after MAL+FRU and 11/13 participants after

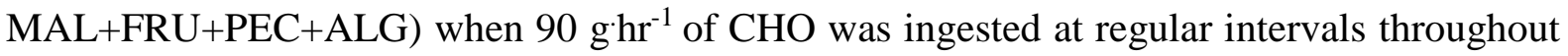
exercise. Our results are in line with previous work that showed formulations of single and multiple transportable CHO mixtures (i.e., $108 \mathrm{ghr}^{-1}$ glucose; 72 and $36 \mathrm{~g} \cdot \mathrm{hr}^{-1}$ glucose plus fructose; 36 and $72 \mathrm{ghr}^{-1}$ glucose plus sucrose) reduce IFABP area under the curve to a similar extent relative to water during 3 hours of low intensity cycling (50\% Wmax; temperate conditions) (Trommelen et al. 2017). Similarly, glucose ingestion (45 ghour ${ }^{-1}, 6 \% \mathrm{w} / \mathrm{v}$ ) attenuated post exercise IFABP concentrations after a 2-hour treadmill run in warm/dry environmental conditions (Snipe, Khoo, Kitic, Gibson, \& Costa, 2017). The increase in postexercise IFABP concentrations have been strongly correlated with splanchnic perfusion (van Wijck et al. 2012), which is reduced during exercise, and further reduced while exercising in hot/humid conditions when blood flow to the skin increased to facilitate heat dissipation (Rowell 1974). The extra loss of total body water and decrease in plasma volume also contributes to the reduction in splanchnic blood flow (Rowell et al. 1968). In the present study, fluid intake could not be personalised to sweat losses because solution concentration can affect hydrogel formation. As a result, a similar degree of hypohydration was observed in all 
experimental conditions ( $\sim 1.5 \%$ body mass loss), indicating that differences in our GI markers were not the result of body-water induced effects to splanchnic blood flow.

Exertional heat stress per se has also been related to the observed magnitude of epithelial damage following exercise, with elevations in deep body temperature strongly correlated to systemic IFABP concentrations (Snipe, Khoo, Kitic, Gibson, \& Costa, 2018). Although previous hydrogel studies have not measured deep body temperature, we can make inferences on the likely temperature responses from similar protocols employed by others. For example, a $\sim 1.4{ }^{\circ} \mathrm{C}$ increase in deep body temperature has been observed during a running protocol similar in duration (120-min), intensity $\left(60 \% \mathrm{VO}_{2} \max \right)$ and environmental conditions $\left(22^{\circ} \mathrm{C}\right.$, 50\% RH; Snipe et al., 2018) to those employed by both McCubbin et al, (2019; 180-min, 60\% $\left.\mathrm{VO}_{2} \max \right)$, and Barber et al, $\left(2020 ; 120-\min , 60 \% \mathrm{VO}_{2} \max \right)$. Similarly, a $\sim 1.4{ }^{\circ} \mathrm{C}$ increase in deep body was also observed after 90 -min of cycling at $55 \% \mathrm{~W}_{\max }$ (Jentjens et al. 2002), and would likely be reflective of the temperature responses encountered during the steady state element of the Mears et al., (2020) experiment (120 min, 55\% Wmax). In comparison, we observed a $\sim 2.2{ }^{\circ} \mathrm{C}$ increase in deep body temperature and peaks of $>39.0{ }^{\circ} \mathrm{C}$ in all trials. We are confident our participants experienced significant exercise induced hyperthermia, which stressed the GI system andprovided us with an experimental scenario in which any potential benefits of pectin-alginate on GI barrier integrity and function could be assessed relative to traditional multiple transportable $\mathrm{CHO}$.

Macronutrient provision has been shown to preserve portal vein blood flow during exercise (Rehrer et al. 2005), suggesting that repeated feeding may stimulate microvascular hyperaemia in the intestinal villi that helps to preserve GI barrier function (Snipe et al., 2017). In the present investigation no differences in deep body temperature were noted between trials, suggesting that postprandial hyperaemia during the $\mathrm{CHO}$ trials may have helped to preserve splanchnic 
perfusion, and as a result, prevented excessive epithelial damage (Snipe et al., 2017). This is important because underperfusion of the gut and subsequent heat-stress induced muscosal damage is likely an important and primary mechanism for endotoxemia and exertional heat stroke (Lim and Mackinnon 2006; Szymanski et al. 2018). Our results support previous research showing that regular $\mathrm{CHO}$ ingestion during exercise can prevent excessive GI permeability when compared to the ingestion of water alone (Lambert, Broussard, Mason, Mauermann, \& Gisolfi, 2001; Snipe et al., 2017). Given the substantial metabolic differences between cycling and running, where alterations in intestinal motility and mechanical trauma (i.e., repetitive jarring associated with running) can further promote epithelial damage and/or dysfunction (Rehrer et al. 2005), evidence derived from cycling cannot be directly extrapolated to running. Future work examining whether hydrogel formulations preserve the GI barrier during prolonged, race-pace running in the heat might therefore be warranted.

The proposed advantages of MAL+FRU+PEC+ALG may only be become apparent when ingestion rates are above current recommendations (e.g. 30-60 $\mathrm{ghr}^{-1}$ for moderate intensity exercise $<2 \mathrm{hr}$ in duration); or in situations associated with GI barrier dysfunction and increased subjective GI symptoms (such as exertional heat stress). Both the incidence and severity of gastrointestinal symptoms reported in previous studies have been low, regardless of how much CHO was provided $\left(78-90 \mathrm{ghr}^{-1} ; 8-18 \% \mathrm{w} / \mathrm{v}\right)$, or which exercise mode were used. Such low symptom incidence/severity make the detection of subtle supplement-mediated differences more challenging. In the present study we report high rates of severe GI discomfort (GI scores over 5) in both the MAL+FRU+PEC+ALG (71\%) and MAL+FRU (57\%) trials relative to water $(36 \%)$. We can therefore be confident that our protocol induced substantial GI distress during each experimental trial relative to previous investigations using both runners (McCubbin et al. 2019; Barber et al. 2020) and cyclists (Baur et al. 2019; Mears et al. 2020a), 
and increases the likelihood of detecting a difference between $\mathrm{CHO}$ drinks. We did note that sensations of gut discomfort were greater following MAL+FRU+PEC+ALG as compared to both the MAL+FRU and WATER. The type of ingested CHO (e.g. solid, liquid, gel) can influence GI comfort (Guillochon and Rowlands 2017) and it has been speculated that hydrogels may cause increased stomach distension that leads to increased sensations of fullness (Baur et al. 2019). Data from the present study do not support this hypothesis, with both CHO drinks producing the same incidence of severe sensations of fullness $(92 \%)$ when compared to water (79\%) alone. As such, the mechanism by which MAL+FRU+PEC+ALG contributed to increased GI discomfort during hyperthermic exercise in the present study remains to be determined.

\section{Strengths and Limitations}

There are two primary reasons why this study is novel. First, to our knowledge this study is the first to evaluate absorption of a multiple-transportable $\mathrm{CHO}$ hydrogel beverage relative to standard multi-transportable $\mathrm{CHO}$ and plain water ingestion during exercise under conditions that are known to promote GI distress (e.g. hot, humid environment). Second, changes in GI barrier function were assessed via blood and urine measurements. The incorporation of male and female participants represents an additional strength of the present study design, as our data provide evidence that the ergogenic benefits of multiple-transportable $\mathrm{CHOs}$ are at least comparable between sexes in the conditions studied. The careful pre-experimental familiarization procedures and inclusion of a water control trial allow us to be confident that our protocol was sensitive enough to detect performance effects. Indeed, both $\mathrm{CHO}$ drinks enhanced TT performance ( $17 \%$ increase in work) at a magnitude above the variability of test 
$(\sim 4 \%)$ relative to water. Therefore, it is unlikely that the lack of difference between $\mathrm{MAL}+\mathrm{FRU}+\mathrm{PEC}+\mathrm{ALG}$ and MAL+FRU is the result of a type 2 error.

However, there are a number of limitations to the present study that should also be acknowledged. First, although participants were asked to replicate their diet and activity levels between trials, this was only confirmed verbally. Thus the possibility these instructions were not adhered to remains. To minimise the effect of macronutrient intake on GI barrier permeability, previous studies have required participants to complete trials after an overnight fast (i.e., Szymanski et al. 2018), or provided a standardized meal (i.e., Snipe et al,. 2017). Because we did not have the resources to provide individualized pre-trial meals, and large differences between habitual intake and a standardized pre-trial diets can lead to alterations in metabolism which also may interfere with performance, we felt it important that participants fuelled in a manner that reflected their own habitual pre-event dietary practices (Jeacocke and Burke 2010). Our decision to use this fairly modest approach was based on the balance of reducing day-to-day variability, minimizing participant burden, and took into consideration other logistical factors (e.g. financial cost, access to participants in the time leading up to an experimental visit).

We also acknowledge that the relatively modest exercise intensity ( $45 \% \mathrm{VO}_{2}$ peak) employed in the present investigation represents a limitation to our study. When conducting pilot work for this investigation, we found that exercise intensities above $50 \% \mathrm{~W}_{\max }$ led to RERs in excess of 1.0, invalidating our calculations of substrate oxidation. Additionally, predicted sweat efficiency also fell below $50 \%$ once exercise intensities were prescribed above 50\% Wmax (due to our inability to match air flow to the simulated cycling speed; Cramer and Jay 2019), We therefore selected a preload exercise intensity which ensured our moderately trained and non-heat acclimated participants could complete the entire exercise bout, without surpassing our ethical deep body temperature cut-off. As a result, the requirement for exogenous $\mathrm{CHO}$ 
provision would have been relatively low, and practical recommendations of 30-60 $\mathrm{ghr}^{-1}$ for exercise under 2-hr in duration may have been sufficient to support performance (Stellingwerff and Cox 2014). However, because others have speculated that the advantages of MAL+FRU+PEC+ALG may only be observable when ingestion rates exceed current recommendations (Pettersson et al. 2019; Mears et al. 2020) we opted to incorporate a more aggressive $\left(90 \mathrm{~g} h r^{-1}\right)$ fuelling strategy. Whilst not aligned to a specific sporting event per-se, our methodology facilitated our primary aim, a mechanistic investigation of enterocyte damage and GI permeability. We cannot discount the potential for MAL+FRU+PEC+ALG to exert beneficial effects during more prolonged and high-intensity exercise which significantly depletes muscle and liver glycogen stores, and which has an increased requirement for exogenous $\mathrm{CHO}$ provision.

\section{Conclusion}

The present study indicates that ingestion of a $16 \% \mathrm{w} / \mathrm{v} \mathrm{CHO}$ mixture (with or without gelling polysaccharides) during submaximal cycling exercise in a hot and humid environment provides an ergogenic benefit during subsequent maximal effort time trial performance. Uniquely, we used an exercise/environmental stimulus designed to induce a high incidence and severity of GI symptoms, alongside the incorporation of assessments of GI barrier function. Our results suggest the ingestion of a multiple-transportable $\mathrm{CHO}$ at a rate of $90 \mathrm{~g} \cdot \mathrm{hr}^{-1}$ does not adversely influence GI barrier integrity, relative to water ingestion, during moderate intensity cycling in hot and humid conditions. No further reductions in IFABP or L/R ratio were shown when gelling polysaccharides were added to the $\mathrm{CHO}$ mixture.

While studies performed at moderate intensities provide valuable mechanistic insights, constraining participants to moderate exercise intensities to minimise measurement artefacts 
does not reflect standard athlete/consumer practice. Future research should aim to incorporate prolonged duration, race-pace protocols at the expense of steady-state measures. Performancefocused approaches could help to determine if there is any context under which pectin-alginate CHO-formulations provide a performance advantage over matched-composition $\mathrm{CHO}$ beverages, or whether clever marketing and endorsements have created a substantial placebo effect in dedicated users.

\section{Acknowledgements}

The authors would like to thank all the participants for volunteering their time and effort in this study. Additionally, we would like to thank Miss Georgina Millward and Mr Ollie Page for assistance in elements of data collection. We also thank contributors to the https://thenounproject.com for images used in Figure 1.

The authors have no conflicts of interest to report.

\section{References}

ASHRAE, A. 2004. Standard 55-2004, Thermal Environmental Conditions for Human Occupancy, Atlanta: American Society of Heating, Refrigerating, and Air-conditioning Engineers. Inc., USA.

Barber, J.F.P., Thomas, J., Narang, B., Hengist, A., Betts, J.A., Wallis, G.A., and Gonzalez, J.T. 2020. Pectin-Alginate Does Not Further Enhance Exogenous Carbohydrate Oxidation in Running. Med. Sci. Sports Exerc. doi:10.1249/MSS.0000000000002262.

Baur, D.A., Toney, H.R., Saunders, M.J., Baur, K.G., Luden, N.D., and Womack, C.J. 2019. 
Carbohydrate hydrogel beverage provides no additional cycling performance benefit versus carbohydrate alone. Eur. J. Appl. Physiol. 119(11-12): 2599-2608. doi:10.1007/s00421-019-04240-4.

Bjarnason, I., Macpherson, A., and Hollander, D. 1995. Intestinal permeability: an overview. Gastroenterology 108(5): 1566-1581. doi:10.1016/0016-5085(95)90708-4

Borg, G.A. 1982. Psychophysical bases of perceived exertion. Med sci Sport. Exerc 14(5): $377-381$.

Costa, R.J.S., Snipe, R.M.J., Kitic, C.M., and Gibson, P.R. 2017. Systematic review: exercise-induced gastrointestinal syndrome-implications for health and intestinal disease. Aliment Pharmacol Ther 46(3): 246-265. doi:10.1111/apt.14157.

Cramer, M.N., and Jay, O. 2014. Selecting the correct exercise intensity for unbiased comparisons of thermoregulatory responses between groups of different mass and surface area. J Appl Physiol 116(9): 1123-1132. doi:10.1152/japplphysiol.01312.2013.

Cramer, M.N., and Jay, O. 2019. Cores of reproducibility in physiology partitional calorimetry. J Appl Physiol 126(2): 267-277. doi:10.1152/japplphysiol.00191.2018.

Febbraio, M.A., Snow, R.J., Hargreaves, M., Stathis, C.G., Martin, I.K., and Carey, M.F. 1994. Muscle metabolism during exercise and heat stress in trained men: effect of acclimation. J. Appl. Physiol. 76(2): 589-597. doi:10.1152/jappl.1994.76.2.589

Frayn, K.N. 1983. Calculation of substrate oxidation rates in vivo from gaseous exchange. J. Appl. Physiol. 55(2): 628-634. doi:10.1152/jappl.1983.55.2.628

Gaskell, S.K., Snipe, R.M.J., and Costa, R.J.S. 2019. Test-Retest Reliability of a Modified Visual Analog Scale Assessment Tool for Determining Incidence and Severity of Gastrointestinal Symptoms in Response to Exercise Stress. Int J Sport Nutr Exerc 
Metab: 1-9. doi:10.1123/ijsnem.2018-0215.

Guillochon, M., and Rowlands, D.S. 2017. Solid, gel, and liquid carbohydrate format effects on gut comfort and performance. Int. J. Sport Nutr. Exerc. Metab. 27(3): 247-254. doi:10.1123/ijsnem.2016-0211.

Jeacocke, N.A., and Burke, L.M. 2010. Methods to standardize dietary intake before performance testing. Int. J. Sport Nutr. Exerc. Metab 20(2):87 103. doi:10.1123/ijsnem.20.2.87.

Jentjens, R.L., Wagenmakers, A.J., and Jeukendrup, A.E. 2002. Heat stress increases muscle glycogen use but reduces the oxidation of ingested carbohydrates during exercise. $\mathbf{J}$ Appl Physiol 92(4): 1562-1572. doi:10.1152/japplphysiol.00482.2001.

Jeukendrup, A.E., Vet-Joop, K., Sturk, A., Stegen, J., Senden, J., Saris, W.H.M., and Wagenmakers, A.J.M. 2000. Relationship between gastro-intestinal complaints and endotoxaemia, cytokine release and the acute-phase reaction during and after a longdistance triathlon in highly trained men. Clin. Sci. 98(1): 47-55.

Kenefick, R.W., Cheuvront, S.N., Palombo, L.J., Ely, B.R., and Sawka, M.N. 2010. Skin temperature modifies the impact of hypohydration on aerobic performance. J Appl Physiol 109(1): 79-86. doi:10.1152/japplphysiol.00135.2010.

Kenny, W.L. (1998). Heat Flux and Storage in Hot Environments. Int. J. Sports Med. (19) Suppl 2:S92-5. doi: 10.1055/s-2007-971966

Lambert, G.P., Broussard, L.J., Mason, B.L., Mauermann, W.J., and Gisolfi, C. V. 2001. Gastrointestinal permeability during exercise: Effects of aspirin and energy-containing beverages. J. Appl. Physiol. 90(6): 2075-2080. doi:10.1152/jappl.2001.90.6.2075.

Lambert, G.P., Lang, J., Bull, A., Pfeifer, P.C., Eckerson, J., Moore, G., Lanspa, S., and 
O’Brien, J. 2008. Fluid restriction during running increases GI permeability. Int J Sport. Med 29(3): 194-198. doi:10.1055/s-2007-965163.

Lim, C.L., and Mackinnon, L.T. 2006. The roles of exercise-induced immune system disturbances in the pathology of heat stroke. Sport. Med. 36(1): 39-64. doi: $10.2165 / 00007256-200636010-00004$

Maxton, D.G., Bjarnason, I., Reynolds, A.P., Catt, S.D., Peters, T.J., and Menzies, I.S. 1986. Lactulose 51Cr-labelled ethylenediaminetetra-acetate, L-rhamnose and polyethyleneglycol 500 as probe markers for assessment in vivo of human intestinal permeability. Clin. Sci. 71(1): 71-80. doi: 10.1042/cs0710071

McCubbin, A.J., Zhu, A., Gaskell, S.K., and Costa, R.J.S. 2019. Hydrogel CarbohydrateElectrolyte Beverage Does Not Improve Glucose Availability, Substrate Oxidation, Gastrointestinal Symptoms or Exercise Performance, Compared With a Concentration and Nutrient-Matched Placebo. Int. J. Sport Nutr. Exerc. Metab.: 1-9. doi:10.1123/ijsnem.2019-0090.

Mears, S.A., Worley, J., Mason, G.S., Hulston, C.J., and James, L.J. 2020a. Addition of sodium alginate and pectin to a carbohydrate-electrolyte solution does not influence substrate oxidation, gastrointestinal comfort or cycling performance. Appl. Physiol. Nutr. Metab.: apnm-2019-0802. doi:10.1139/apnm-2019-0802.

Moran, D.S., Shitzer, A., and Pandolf, K.B. 1998. A physiological strain index to evaluate heat stress. Am. J. Physiol. Integr. Comp. Physiol. 275(1): R129-R134. doi: 10.1152/ajpregu.1998.275.1.R129

de Oliveira, E.P., and Burini, R.C. 2014. Carbohydrate-dependent, exercise-induced gastrointestinal distress. Nutrients 6(10): 4191-4199. doi:10.3390/nu6104191. 
Pettersson, S., Edin, F., Bakkman, L., and McGawley, K. 2019. Effects of supplementing with an $18 \%$ carbohydrate-hydrogel drink versus a placebo during whole-body exercise in $-5{ }^{\circ} \mathrm{C}$ with elite cross-country ski athletes: A crossover study. J. Int. Soc. Sports Nutr. 16(1): 46. doi:10.1186/s12970-019-0317-4.

Rehrer, N.J., Goes, E., DuGardeyn, C., Reynaert, H., and DeMeirleir, K. 2005. Effect of Carbohydrate on Portal Vein Blood Flow During Exercise. Int. J. Sports Med. 26(3): 171-176. doi:10.1055/s-2004-820957.

Rowell, L.B. 1974. Human cardiovascular adjustments to exercise and thermal stress. Physiol. Rev. 54(1): 75-159. doi: 10.1152/physrev.1974.54.1.75

Rowell, L.B., Brengelmann, G.L., Blackmon, J.R., Twiss, R.D., and Kusumi, F. 1968. Splanchnic blood flow and metabolism in heat-stressed man. J. Appl. Physiol. 24(4): 475-484. doi: 10.1152/jappl.1968.24.4.475

Rowlands, D.S., Houltham, S., Musa-Veloso, K., Brown, F., Paulionis, L., and Bailey, D. 2015. Fructose-Glucose Composite Carbohydrates and Endurance Performance: Critical Review and Future Perspectives. Sport. Med 45(11): 1561-1576. doi:10.1007/s40279015-0381-0.

Snipe, R.M.J., Khoo, A., Kitic, C.M., Gibson, P.R., and Costa, R.J.S. 2017. Carbohydrate and protein intake during exertional heat stress ameliorates intestinal epithelial injury and small intestine permeability. Appl. Physiol. Nutr. Metab. 42(12): 1283-1292. doi:10.1139/apnm-2017-0361.

Snipe, R.M.J., Khoo, A., Kitic, C.M., Gibson, P.R., and Costa, R.J.S. 2018. The impact of exertional-heat stress on gastrointestinal integrity, gastrointestinal symptoms, systemic endotoxin and cytokine profile. Eur J Appl Physiol 118(2): 389-400. doi:10.1007/s00421-017-3781-z. 
Stellingwerff, T., and Cox, G.R. 2014. Systematic review: Carbohydrate supplementation on exercise performance or capacity of varying durations. Appl. Physiol. Nutr. Metab. 39(9):998-1011. doi:10.1139/apnm-2014-0027.

Sutehall, S., Muniz-Pardos, B., Bosch, A.N., Di Gianfrancesco, A., and Pitsiladis, Y.P. 2018. Sports Drinks on the Edge of a New Era. Curr. Sports Med. Rep. 17(4): 112-116. doi: 10.1249/JSR.0000000000000475

Szymanski, M.C., Gillum, T.L., Gould, L.M., Morin, D.S., and Kuennen, M.R. 2018. Shortterm dietary curcumin supplementation reduces gastrointestinal barrier damage and physiological strain responses during exertional heat stress. J Appl Physiol 124(2): 330 340. doi:10.1152/japplphysiol.00515.2017.

Tikuisis, P., McLellan, T.M., and Selkirk, G. 2002. Perceptual versus physiological heat strain during exercise-heat stress. Med. Sci. Sports Exerc. 34(9): 1454-1461. doi:10.1097/00005768-200209000-00009.

Trommelen, J., Fuchs, C., Beelen, M., Lenaerts, K., Jeukendrup, A., Cermak, N., and van Loon, L. 2017. Fructose and Sucrose Intake Increase Exogenous Carbohydrate Oxidation during Exercise. Nutrients 9(2): 167. doi:10.3390/nu9020167.

Vandenbogaerde, T.J., and Hopkins, W.G. 2011. Effects of Acute Carbohydrate Supplementation on Endurance Performance. Sport. Med. 41(9): 773-792. doi:10.2165/11590520-000000000-00000.

van Wijck, K., Lenaerts, K., Grootjans, J., Wijnands, K.A.P., Poeze, M., van Loon, L.J.C., Dejong, C.H.C., and Buurman, W.A. 2012. Physiology and pathophysiology of splanchnic hypoperfusion and intestinal injury during exercise: strategies for evaluation and prevention. Am. J. Physiol. Liver Physiol. 303(2): G155-G168. doi: 10.1152/ajpgi.00066.2012 
Table 1. Physiological responses during the 90-minute cycling protocol, and end of the 15 min TT $(n=14)$. Data are displayed as mean \pm SD

\begin{tabular}{|c|c|c|c|c|c|c|}
\hline Variable & Condition & 30 min & $60 \mathrm{~min}$ & $90 \min$ & Time trial & Condition $\mathrm{x}$ time interaction \\
\hline \multirow{5}{*}{ Carbon dioxide production $\left(\mathrm{L} \cdot \mathrm{min}^{-1}\right)$} & WATER & $1.82 \pm 0.30$ & $1.89 \pm 0.33$ & $2.01 \pm 0.33$ & NA & $\mathrm{F}_{(16,240)}=0.83, \mathrm{p}=0.65$ \\
\hline & MAL+FRU+PEC+ALG & $1.80 \pm 0.31$ & $1.86 \pm 0.33$ & $1.93 \pm 0.34$ & NA & $\mathrm{C}$ \\
\hline & MAL+FRU & $1.89 \pm 0.36$ & $1.91 \pm 0.33$ & $2.02 \pm 0.43$ & NA & \\
\hline & MAL+FRU+PEC+ALG & $1.68 \pm 0.28$ & $1.75 \pm 0.26$ & $1.80 \pm 0.28$ & NA & \\
\hline & MAL+FRU & $1.75 \pm 0.32$ & $1.78 \pm 0.31$ & $1.86 \pm 0.41$ & NA & \\
\hline \multirow[t]{3}{*}{ Respiratory exchange ratio } & WATER & $0.91 \pm 0.05$ & $0.88 \pm 0.04$ & $0.86 \pm 0.04$ & NA & $F_{(2,30)}=7.61, p=0.002$ \\
\hline & MAL+FRU+PEC+ALG & $0.94 \pm 0.02$ & $0.94 \pm 0.04 *$ & $0.93 \pm 0.03 *$ & NA & \\
\hline & MAL+FRU & $0.93 \pm 0.04$ & $0.93 \pm 0.03^{*}$ & $0.92 \pm 0.04^{*}$ & NA & \\
\hline \multirow[t]{3}{*}{ Heart rate (beats $\min ^{-1}$ ) } & WATER & $134 \pm 17$ & $148 \pm 18$ & $152 \pm 15$ & $177 \pm 9$ & $\mathrm{~F}_{(22,286)}=1.26, \mathrm{p}=0.19$ \\
\hline & MAL+FRU+PEC+ALG & $134 \pm 14$ & $143 \pm 17$ & $148 \pm 15$ & $179 \pm 8$ & \\
\hline & MAL+FRU & $134 \pm 14$ & $144 \pm 15$ & $150 \pm 14$ & $181 \pm 8$ & \\
\hline \multirow[t]{3}{*}{ Core temperature $\left({ }^{\circ} \mathrm{C}\right)$} & WATER & $38.23 \pm 0.28$ & $38.47 \pm 0.25$ & $38.65 \pm 0.22$ & $39.13 \pm 0.19$ & $\mathrm{~F}_{(22,427)}=0.38, \mathrm{p}=0.99$ \\
\hline & MAL+FRU+PEC+ALG & $38.17 \pm 0.27$ & $38.45 \pm 0.24$ & $38.65 \pm 0.20$ & $39.16 \pm 0.21$ & \\
\hline & MAL+FRU & $38.15 \pm 0.32$ & $38.46 \pm 0.27$ & $38.71 \pm 0.18$ & $39.18 \pm 0.15$ & \\
\hline \multirow[t]{2}{*}{ Mean skin temperature $\left({ }^{\circ} \mathrm{C}\right)$} & WATER & $34.91 \pm 0.47$ & $34.76 \pm 0.50$ & $34.75 \pm 0.61$ & NA & $\mathrm{F}_{(20,385)}=0.65, \mathrm{p}=0.88$ \\
\hline & MAL+FRU & $34.85 \pm 0.45$ & $34.75 \pm 0.42$ & $34.89 \pm 0.52$ & NA & \\
\hline \multirow[t]{3}{*}{ Mean body temperature $\left({ }^{\circ} \mathrm{C}\right)$} & WATER & $37.57 \pm 0.22$ & $37.73 \pm 0.22$ & $37.87 \pm 0.25$ & NA & $\mathrm{F}_{(20,384)}=0.67, \mathrm{p}=0.85$ \\
\hline & MAL+FRU+PEC+ALG & $37.49 \pm 0.17$ & $37.70 \pm 0.20$ & $37.88 \pm 0.23$ & NA & \\
\hline & MAL+FRU & $37.49 \pm 0.20$ & $37.72 \pm 0.19$ & $37.90 \pm 0.18$ & NA & \\
\hline \multirow[t]{6}{*}{ Physiological strain index (A.U) } & WATER & $5.3 \pm 0.9$ & $6.2 \pm 1.1$ & $6.8 \pm 0.9$ & $8.8 \pm 0.6$ & $F_{(16,310)}=0.24, p=0.65$ \\
\hline & MAL+FRU+PEC+ALG & $5.2 \pm 0.8$ & $6.1 \pm 1.0$ & $6.7 \pm 0.9$ & $9.0 \pm 0.5$ & \\
\hline & MAL+FRU & $5.3 \pm 0.8$ & $6.3 \pm 0.9$ & $6.9 \pm 0.7$ & $9.2 \pm 0.3$ & \\
\hline & WATER & $12 \pm 1$ & $14 \pm 2$ & $15 \pm 2$ & $20 \pm 2$ & $\mathrm{~F}_{(18,351)}=0.96, \mathrm{p}=0.51$ \\
\hline & MAL+FRU+PEC+ALG & $12 \pm 1$ & $13 \pm 2$ & $15 \pm 2$ & $20 \pm 2$ & \\
\hline & MAL+FRU & $12 \pm 1$ & $13 \pm 2$ & $15 \pm 2$ & $20 \pm 2$ & \\
\hline \multirow[t]{3}{*}{ Thermal sensation } & WATER & $2 \pm 1$ & $2 \pm 1$ & $2 \pm 1$ & $3 \pm 1$ & $\mathrm{~F}_{(20,390)}=0.41, \mathrm{p}=0.98$ \\
\hline & MAL+FRU+PEC+ALG & $2 \pm 1$ & $2 \pm 1$ & $3 \pm 1$ & $3 \pm 1$ & \\
\hline & MAL+FRU & $2 \pm 1$ & $2 \pm 1$ & $2 \pm 1$ & $3 \pm 1$ & \\
\hline \multirow[t]{3}{*}{ Thermal comfort } & WATER & $6 \pm 1$ & $7 \pm 1$ & $8 \pm 1$ & $8 \pm 1$ & $\mathrm{~F}_{(20,390)}=0.56, \mathrm{p}=0.94$ \\
\hline & $\mathrm{MAL}+\mathrm{FRU}+\mathrm{PEC}+\mathrm{ALG}$ & $6 \pm 1$ & $7 \pm 1$ & $7 \pm 1$ & $8 \pm 1$ & \\
\hline & MAL+FRU & $6 \pm 1$ & $7 \pm 1$ & $7 \pm 1$ & $8 \pm 1$ & \\
\hline
\end{tabular}


Table 2. Gastrointestinal symptom incidence and severity scores reported during the 90 -minute cycling protocol, while consuming either water, a $16 \%$ w/v MAL+FRU+PEC+ALG or a 16\% w/v MAL+FRU. Data show the mean (range within an individual participant). Variables highlighted in bold indicate 3 differences when compared to the WATER trial.

\begin{tabular}{|c|c|c|c|c|c|c|c|c|c|c|}
\hline & \multicolumn{3}{|c|}{ WATER } & \multicolumn{3}{|c|}{ MAL+FRU+PEC+ALG } & \multicolumn{3}{|c|}{ MAL+FRU } & \multirow[t]{2}{*}{ Friedman p-value } \\
\hline & $\begin{array}{r}\text { Incidence } \\
\text { (Total) }\end{array}$ & $\begin{array}{r}\text { Incidence } \\
\text { (Severe) }\end{array}$ & $\begin{array}{r}\text { Total } \\
\text { symptoms }\end{array}$ & $\begin{array}{r}\text { Incidence } \\
\text { (Total) }\end{array}$ & $\begin{array}{r}\text { Incidence } \\
\text { (Severe) }\end{array}$ & Total symptoms & $\begin{array}{r}\text { Incidence } \\
\text { (Total) }\end{array}$ & $\begin{array}{r}\text { Incidence } \\
\text { (Severe) }\end{array}$ & $\begin{array}{r}\text { Total } \\
\text { symptoms }\end{array}$ & \\
\hline Gut comfort & 11 & 5 & $56(0-10)$ & 14 & 10 & $117(2-17)$ & 14 & 8 & $85(2-11)$ & 0.006 \\
\hline Gut Fullness & 14 & 11 & $122(4-27)$ & 14 & 13 & $183(4-32)$ & 14 & 13 & $158(4-30)$ & $<0.0001$ \\
\hline Thirst & 13 & 12 & $159(0-34)$ & 14 & 9 & $115(0-19)$ & 14 & 12 & $132(0-19)$ & 0.186 \\
\hline Total GI symptoms & NA & 84 & 494 & NA & 105 & 678 & NA & 94 & 624 & 0.156 \\
\hline \multicolumn{11}{|l|}{ Upper GI symptoms } \\
\hline Belching & 8 & 1 & $27(0-7)$ & 13 & 8 & $83(0-10)$ & 12 & 4 & $60(0-13)$ & 0.024 \\
\hline Heart burn & 1 & 0 & $4(0-4)$ & 4 & 2 & $14(0-6)$ & 3 & 1 & $11(0-8)$ & 0.369 \\
\hline Bloating & 8 & 2 & $24(0-7)$ & 11 & 7 & $72(0-12)$ & 7 & 2 & $38(0-14)$ & 0.035 \\
\hline Upper abdominal Pain & 2 & 0 & $7(0-5)$ & 5 & 1 & $15(0-7)$ & 4 & 1 & $12(0-6)$ & 0.142 \\
\hline Urge to vomit & 3 & 1 & $14(0-8)$ & 2 & 0 & $3(0-2)$ & 4 & 1 & $15(0-8)$ & 0.229 \\
\hline Vomit & 1 & 0 & $5(0-5)$ & 1 & 0 & $1(0-1)$ & 2 & 0 & $8(0-5)$ & 0.223 \\
\hline \multicolumn{11}{|l|}{ Lower GI symptoms } \\
\hline Flatulence & 4 & 1 & $18(0-11)$ & 8 & 2 & $36(0-9)$ & 5 & 2 & $22(0-10)$ & 0.135 \\
\hline Urge to defecate & 3 & 0 & $8(0-5)$ & 5 & 0 & $9(0-4)$ & 6 & 2 & $22(0-8)$ & 0.165 \\
\hline Abdominal pain & 2 & 0 & $6(0-5)$ & 4 & 1 & $12(0-7)$ & 1 & 0 & $4(0-4)$ & 0.162 \\
\hline \multicolumn{11}{|l|}{ Other symptoms } \\
\hline Nausea & 4 & 2 & $19(0-7)$ & 4 & 1 & $7(0-3)$ & 5 & 2 & $16(0-7)$ & 0.738 \\
\hline Dizziness & 4 & 2 & $21(0-7)$ & 4 & 0 & $7(0-3)$ & 1 & 1 & $7(0-7)$ & 0.084 \\
\hline Abdominal stitch & 6 & 0 & $3(0-2)$ & 2 & 0 & $4(0-2)$ & 2 & 1 & $7(0-5)$ & 0.939 \\
\hline
\end{tabular}




\section{Figure legends}

Figure 1. Schematic representation of the experimental design and timeline for physiological, subjective and biochemical measures. PSI: physiological strain index, RPE: rating of perceived exertion, TS: Thermal sensation.

Figure 2. Individual time-trial performance data for carbohydrate trials (MAL+FRU+PEC+ALG, MAL+FRU) plotted against the line of no difference (A). $\delta$ represent the male participants and $q$ represent the female participants. It should be noted the consistency that data points fall above the line of no difference, regardless of $\mathrm{CHO}$ drink consumed. Though not powered to examine sex differences, this data suggests both men and women benefit from the ingesting of multiple transportable CHO during exercise in hot humid conditions. Individual data for total work $(\mathrm{kJ})$ completed during each 15 -minute time trial and the groups means are displayed in panel B. Bars denote the mean response and error bars display the standard deviation.

Figure 3. Fold change in serum IFABP concentrations $(A, n=13)$ and urinary lactulose/rhamnose ratio (B, $\mathrm{n}=12$ ), following 90 minutes of cycling exercise. Lines show individual responses and the bars represent the group mean values. and error bars display the standard deviation.

Figure 4. Mean \pm SD whole body fat oxidation (A) and whole body carbohydrate oxidation (B) rates; and mean \pm SD blood glucose (C) and blood lactate (D) concentrations throughout the cycling protocol $(n=14)$. 


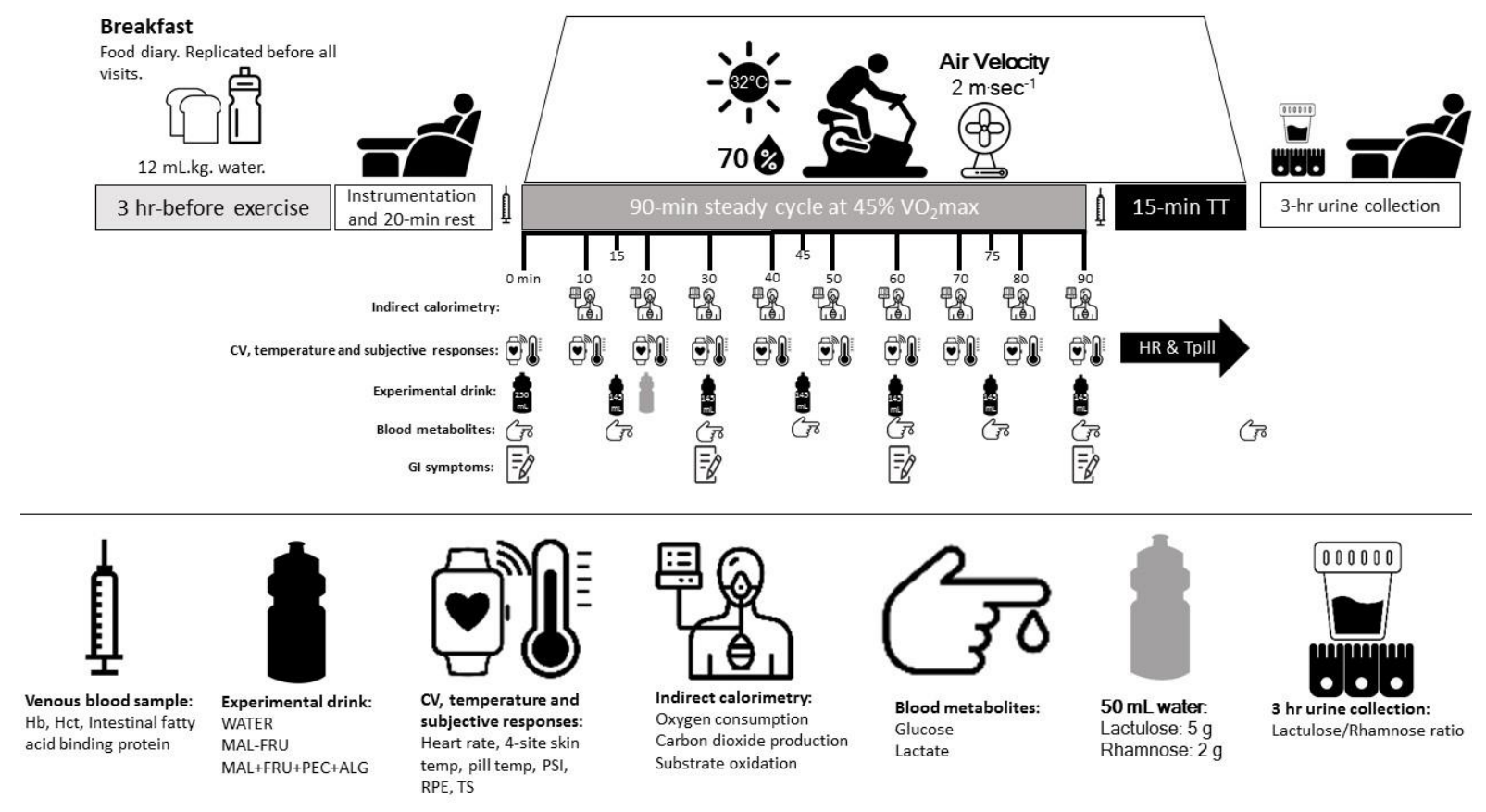

Fig. 1 


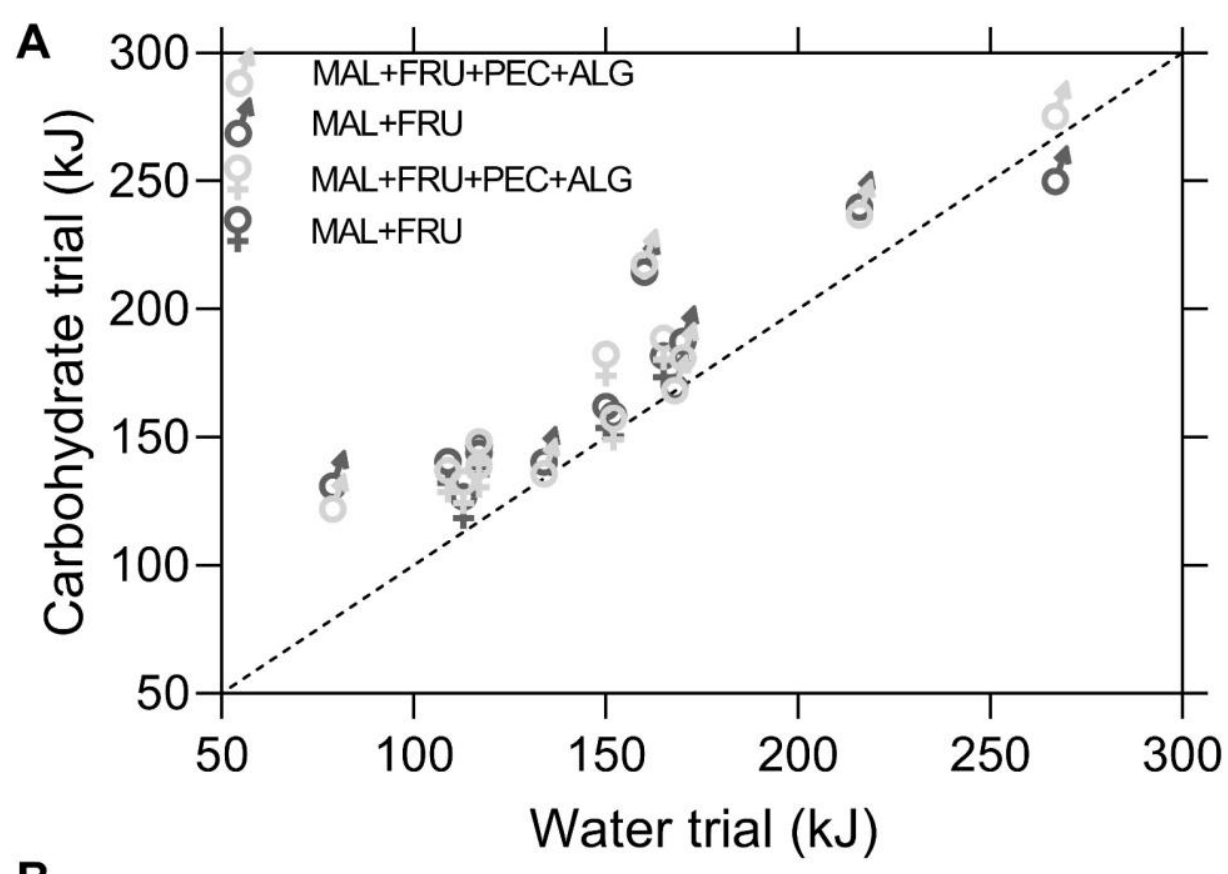

B

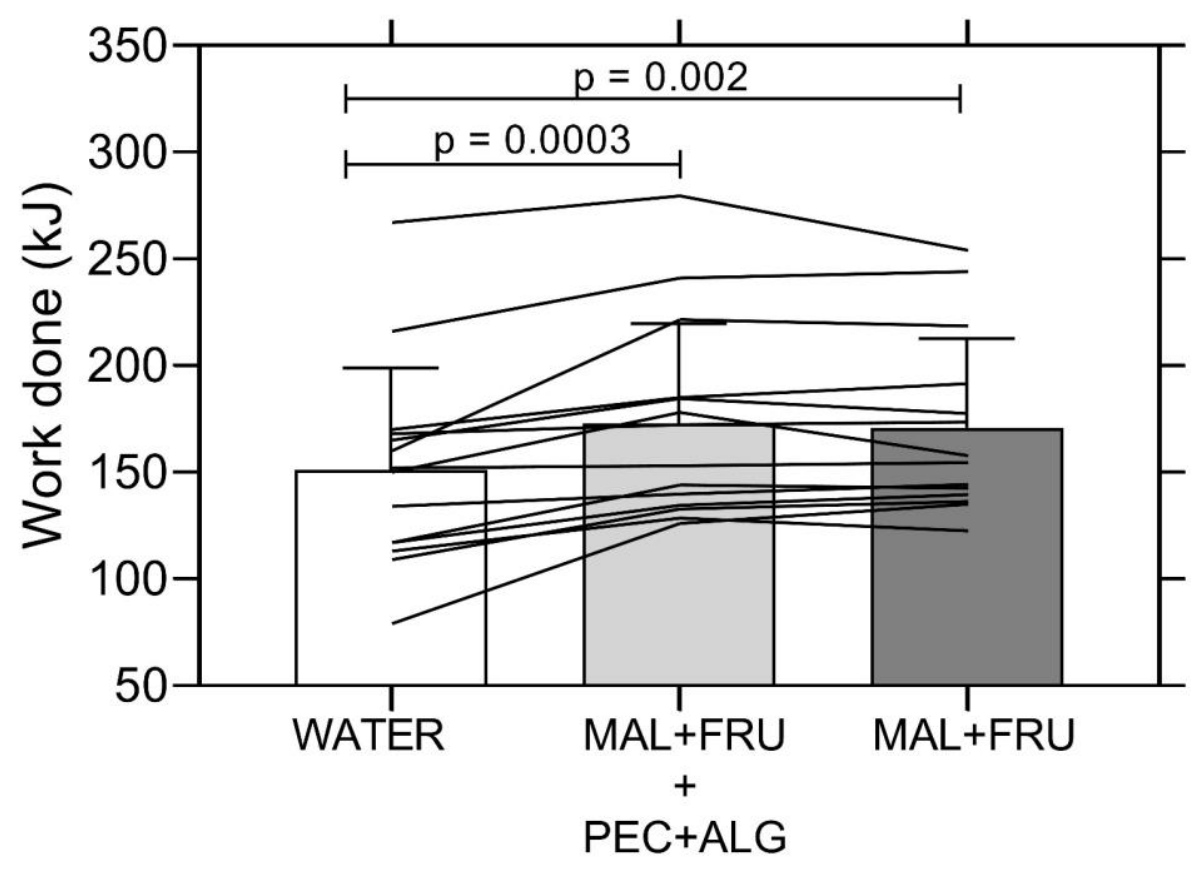

Fig 2. 

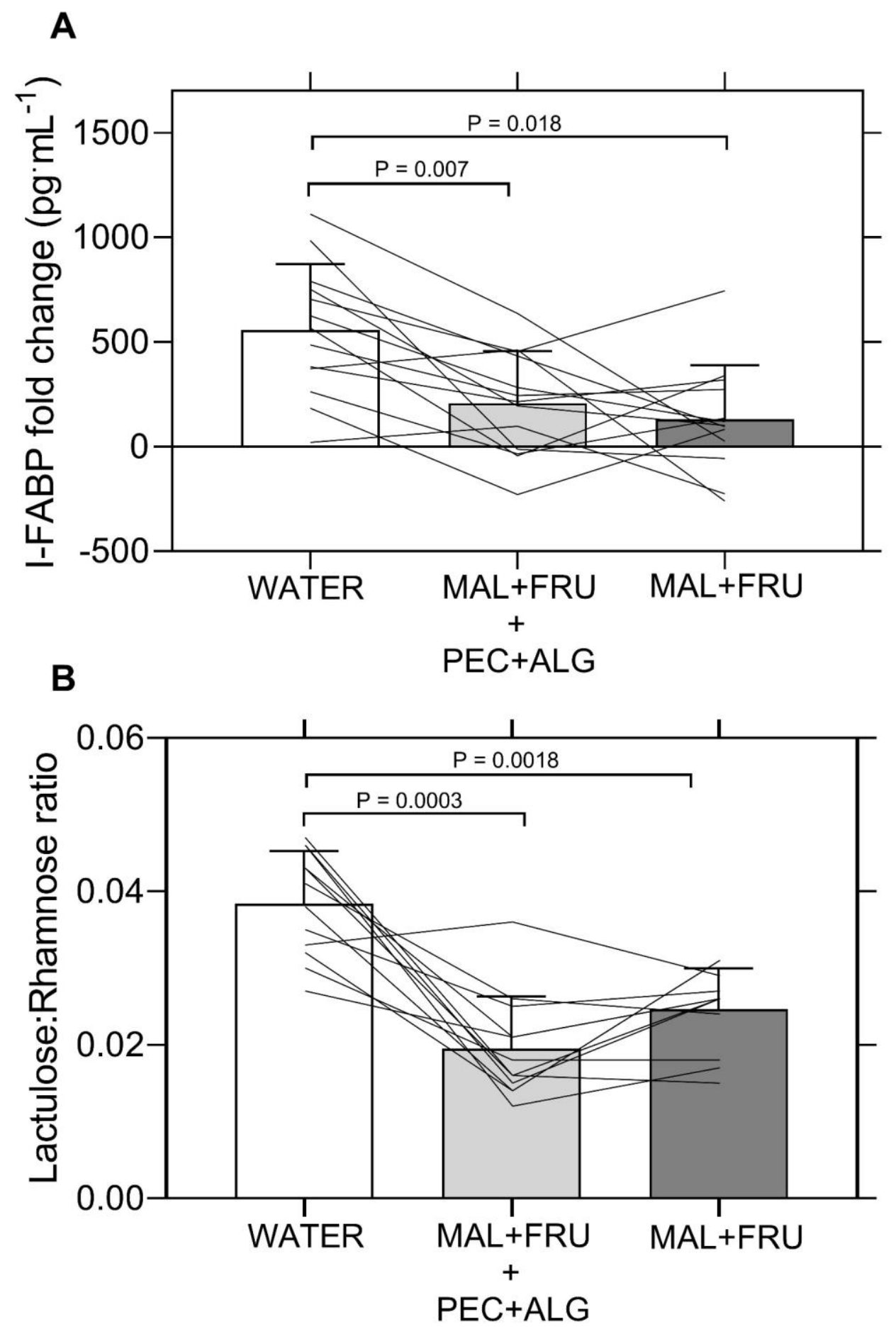

Fig 3. 

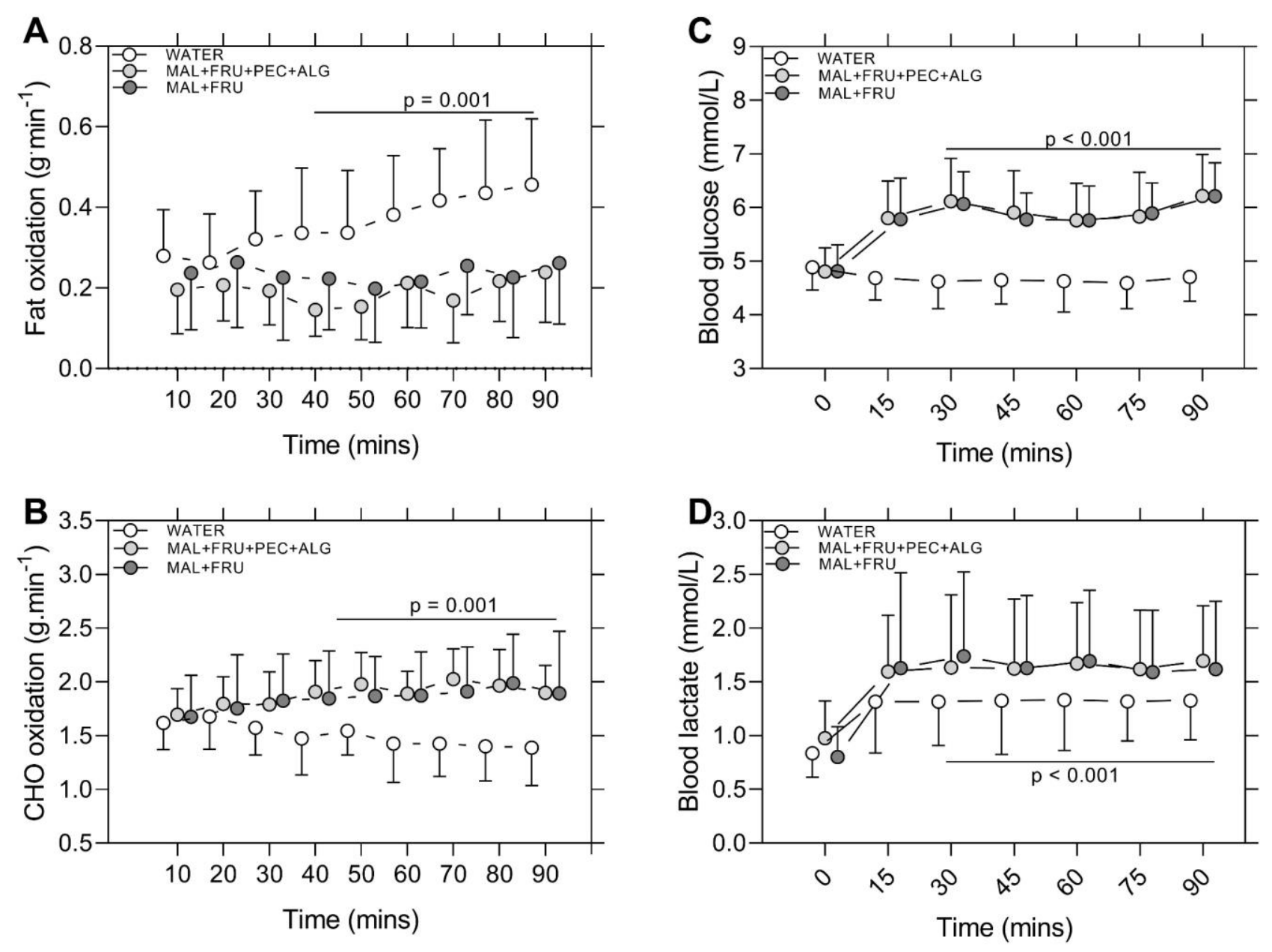

Fig 4. 